\title{
Neurological Complications of Ebola Virus Infection
}

\author{
Bridgette Jeanne Billioux ${ }^{1}$ (D) $\cdot$ Bryan Smith $^{1} \cdot$ Avindra Nath $^{1}$
}

Published online: 13 July 2016

(C) The American Society for Experimental NeuroTherapeutics, Inc. (outside the U.S.) 2016

\begin{abstract}
Ebola virus disease is one of the deadliest pathogens known to man, with a mortality rate between $25-90 \%$ depending on the species and outbreak of Ebola. Typically, it presents with fever, headache, voluminous vomiting and diarrhea, and can progress to a hemorrhagic illness; neurologic symptoms, including meningoencephalitis, seizures, and coma, can also occur. Recently, an outbreak occurred in West Africa, affecting $>28,000$ people, and killing $>11,000$. Owing to the magnitude of this outbreak, and the large number $(>17,000)$ of Ebola survivors, the medical and scientific communities are learning much more about the acute manifestations and sequelae of Ebola. A number of neurologic complications can occur after Ebola, such as seizures, memory loss, headaches, cranial nerve abnormalities, and tremor. Ebola may also persist in some immunologically privileged sites, including the central nervous system, and can rarely lead to relapse in disease. Owing to these findings, it is important that survivors are evaluated and monitored for neurologic symptoms. Much is unknown about this disease, and treatment remains largely supportive; however, with ongoing clinical and basic science, the mechanisms of how Ebola affects the central nervous system and how it persists after acute disease will hopefully become more clear, and better treatments and clinical practices for Ebola patients will be developed.
\end{abstract}

Electronic supplementary material The online version of this article (doi:10.1007/s13311-016-0457-z) contains supplementary material, which is available to authorized users.

Avindra Nath

natha@ninds.nih.gov

1 Section of Infections of the Nervous System, National Institute of Neurological Diseases and Stroke, National Institutes of Health, Bethesda, MD, USA
Key Words Ebola $\cdot$ meningitis $\cdot$ encephalitis $\cdot$ microvascular disease $\cdot$ deafness $\cdot$ vertigo $\cdot$ insomnia $\cdot$ cognition $\cdot$ magnetic resonance imaging

\section{Introduction}

Filoviruses have come to global attention recently with the large outbreak of Ebola virus disease (EVD) originating in Guinea in West Africa beginning in December 2013. Filoviruses, which include the various Ebola species (Zaire, Bundibugyo, Reston, Sudan, and Tai Forest) and Marburg virus, are some of the most deadly pathogens known to infect humans, with mortality rates ranging between $25 \%$ and $90 \%$ $[1,2]$. They were first discovered in 1967, when researchers in Germany and Yugoslavia developed hemorrhagic fever after handling green monkey specimens; the virus that was subsequently isolated from these cases was called Marburg virus, after the city in Germany where most of the cases occurred [3]. A little less than a decade later, in 1976, Ebola virus was identified as the cause of 2 outbreaks of highly fatal hemorrhagic fever in northern Zaire [now Democratic Republic of Congo (DRC)] and southern Sudan; the virus takes its name from the Ebola River, which runs near the village of Yambuku, where the first outbreak took place [1]. After these initial outbreaks, subsequent outbreaks of Marburg virus and Ebola virus occurred sporadically in different parts of Africa, primarily central Africa, including Marburg virus outbreaks in the DRC in 1999 and Angola in 2005, and Ebola virus outbreaks in Kikwit (DRC), in 1995, Gulu (Uganda) in 2000, and Bundibugyo (Uganda) in 2008. These various outbreaks occurred largely in rural areas and were relatively small, affecting between $<10$ and 425 patients per outbreak [2]. However, in December 2013, an Ebola [Zaire ebolavirus (EBOV)] outbreak occurred in Guinea in West Africa and rapidly spread to 
other parts of West Africa, including areas of high population density, primarily in Liberia and Sierra Leone; the outbreak also included some imported but generally well-contained cases in Nigeria, Spain, and the USA [1]. It has become the largest outbreak in history, with 28,639 cases and 11,316 deaths due to EVD as of 17 February 2016 [4]. With thousands of EVD survivors, the medical and scientific communities are learning more about the natural history of EVD than ever before. In particular, sequelae of Ebola are becoming more and more apparent, including ophthalmologic, rheumatologic, and neurologic sequelae. The persistence of Ebola virus and the potential for EVD relapse are also becoming more evident. Further knowledge and education about these fascinating emerging/re-emerging infectious diseases are warranted to continue surveillance and potential treatment of current survivors, as well as to prevent other outbreaks from occurring or from spreading, given modern day trends in global travel.

\section{Virological Properties}

Ebola virus is a negative-strand RNA virus that is $19 \mathrm{~kb}$ in size. It has 7 structural proteins (NP, VP-24, 30, 35, and 40) and 1 nonstructural protein (L5). The virus mainly infects macrophages and endothelial cells and uses the $\mathrm{C} 1$ protein associated with Niemann-Picks disease as a receptor. Thus, cells derived from patients with Niemann-Pick disease are resistant to infection by the virus. Several species of the virus have been identified, which have been associated with different outbreaks. The Zaire strain has a 70-90\% mortality rate. In comparison, the mortality rate for the Sudan virus is $50 \%$ and the Bundibugyo virus is $25 \%$.

Bats are thought to be the major reservoir of the virus. They can either directly infect humans or the bats may infect wild animals that may then serve as an intermediary host. Humanto-human transmission is the major cause of the spread of the infection [5]. The virus is shed in all bodily fluids, including saliva, tears, sweat, urine, semen, and even ear wax.

\section{Clinical Properties}

\section{Transmission}

Human-to-human transmission of Ebola virus usually occurs through direct contact between infectious body fluids of a patient with symptomatic EVD and mucous membranes and/ or broken skin of an uninfected individual [6]. During acute illness, Ebola virus can be detected in many body fluids, including blood, excrement, vomitus, sweat, breast milk, vaginal secretions, and semen [7]. However, at different stages of the disease, these body fluids have varying levels of infectivity. The incubation period, which is the period of time between infection with Ebola virus and first symptom onset, is usually 4 to 10 days, but may be as brief as 2 days or as long as 21 days; during this time, risk of transmission of the virus is essentially zero [8, 9]. During the first few days of symptomatic disease, transmission seems to remain low; however, as the disease progresses, infectivity and potential for transmission increases significantly. During this period, viral loads in various bodily fluids increase exponentially, with viral loads reaching as high as billions of copies per milliliter of blood late in the disease [10]. Infected patients also produce large quantities of infectious bodily fluids, as explosive diarrhea and vomiting become more common as the infection progresses [11].

As Ebola virus can remain viable in liquid or dried material for many days, transmission can occur from dead patients with EVD or from improper handling of waste materials from patients with EVD [12]. Given these factors, people at highest risk for contracting EVD tend to be the people who are actively taking care of patients with EVD such as healthcare workers or other caretakers, people who are in close contact with patients with EVD in later stages of infection, and people who come into direct contact with dead patients with EVD, through burial or funeral practices $[2,13]$. Although seemingly rare, Ebola can also be transmitted through sexual contact, even in the convalescent phase, as Ebola virus can persist in semen for months after recovery from the illness [14]. A case of Ebola occurred in a woman in March 2015 whose only known Ebola contact was via unprotected sex with an EVD survivor; after genetic analysis it was confirmed that survivor's and the patient's Ebola virus genomes were identical and that the transmission likely occurred from sexual contact [15]. Butchering and handling of bushmeat, including nonhuman primates and bats, have also previously been associated with outbreaks of Ebola [16]. Aerosolized transmission of Ebola has not been established as a cause of disease in humans, although this mode of transmission has been described in monkeys [17]. In most cases, prevention of transmission is achieved by appropriate barrier precautions and disinfection when dealing with patients with EVD and their waste. See Table 1 for a summary of epidemiological risk factors for EVD.

\section{Clinical Manifestations of Acute Infection: Symptoms and Signs}

Early EVD symptoms are relatively nonspecific and typically include a high fever, malaise, fatigue, headache, and generalized body aches. Symptoms may begin abruptly and progress over a few days to include abdominal pain, nausea, and highvolume vomiting and diarrhea. Other associated signs and symptoms include conjunctival injection, chest pain, arthralgias, myalgias, asthenia, and hiccoughs [7, 18]. Early in the disease course, symptoms may be mistaken for other tropical 
Table 1 Epidemiologic risk factors for Ebola virus disease (EVD) [7]

\begin{tabular}{|c|c|}
\hline \multirow[t]{5}{*}{ High risk } & - Percutaneous or mucous membrane exposure to body fluids of a patient with EVD \\
\hline & - Exposure to body fluids of a patient with EVD without appropriate PPE \\
\hline & $\begin{array}{l}\text { - Processing body fluids of a patient with EVD without PPE or standard biosafety } \\
\text { precautions }\end{array}$ \\
\hline & $\begin{array}{l}\text { - Direct contact without appropriate PPE with a dead body in a country with widespread } \\
\text { EBOV transmission }\end{array}$ \\
\hline & - Having lived in the same house and provided care to a symptomatic patient with EVD \\
\hline \multirow[t]{2}{*}{ Some Risk } & $\begin{array}{l}\text { - Direct contact with a symptomatic patient with EVD while using appropriate PPE in a } \\
\text { country with widespread EBOV }\end{array}$ \\
\hline & $\begin{array}{l}\text { - Close contact with a symptomatic patient with EVD in households, healthcare } \\
\text { facilities, or community settings }\end{array}$ \\
\hline \multirow[t]{5}{*}{$\begin{array}{l}\text { Low (but not zero) } \\
\text { risk }\end{array}$} & $\begin{array}{l}\text { - Having been in a country with widespread EVD transmission within the past } 21 \text { days } \\
\text { without a known exposure }\end{array}$ \\
\hline & $\begin{array}{l}\text { - Having brief direct contact (shaking hands, etc.) while not wearing PPE with a patient } \\
\text { with EVD while they are in the early stages of disease }\end{array}$ \\
\hline & $\begin{array}{l}\text { - Being in close proximity with a symptomatic patient with EVD for a brief period of } \\
\text { time }\end{array}$ \\
\hline & $\begin{array}{l}\text { - Direct contact with a patient with EVD while using appropriate PPE in a country } \\
\text { without widespread EBOV }\end{array}$ \\
\hline & - Having traveled on an aircraft with a symptomatic patient with EVD \\
\hline \multirow{4}{*}{$\begin{array}{l}\text { No identifiable } \\
\text { risk }\end{array}$} & - Contact with an asymptomatic person who had contact with a patient with EVD \\
\hline & $\begin{array}{l}\text { - Contact with an asymptomatic person who had contact with a symptomatic patient } \\
\text { with EVD }\end{array}$ \\
\hline & - Having been in a country with widespread EBOV transmission $>$ than 21 days ago \\
\hline & $\begin{array}{l}\text { - Having been in a country without widespread EBOV transmission but without any } \\
\text { exposures defined above }\end{array}$ \\
\hline
\end{tabular}

diseases, such as malaria, dengue, or cholera [19]. A recent account of an Ebola treatment unit (ETU) in Monrovia, Liberia, describes the typical output from a patient with EVD as an estimate of 5 liters or more of watery diarrhea per day, lasting for up to 7 days and sometimes longer [11]. This profuse vomiting and diarrhea can quickly lead to intravascular volume depletion, electrolyte disorders, hypoperfusion, and shock [20]. Although Ebola has been traditionally known as a hemorrhagic fever, hemorrhagic manifestations are a late complication, and may be seen in only a minority of patients [20]. These symptoms include petechiae, ecchymosis, oozing from venipuncture sites, mucosal hemorrhage, hematemesis, or melena [7]. Women who are pregnant may have spontaneous abortions associated with significant bleeding [21].

\section{Acute Neurologic Manifestations}

In the acute phase, patients with EVD may present with a number of neurologic signs and symptoms, although serious neurologic manifestations are relatively infrequent. Most commonly, patients will complain of a nonspecific headache, which often presents as an early symptom. Altered mental status, from mild confusion to delirium with hallucinations, may also occur, but may be secondary to a host of variables, including electrolyte abnormalities and shock. In severe cases, coma may occur [18]. Meningitis and encephalitis related to EVD have also been reported in the recent outbreak, as well as in prior outbreaks, although the incidence is not well documented [22-24]. During acute EVD, seizures have also been reported, although these are not well characterized [11].

Detailed neurological evaluations and investigations have been hard to perform on acutely ill patients in endemic regions. However, 1 patient admitted to the National Institutes of Health (NIH) was studied extensively. He developed profound muscle weakness in the first week of the illness, requiring intubation and ventilatory support. This was followed by meningoencephalitis as manifested by classical meningeal signs, delirium, eye movement abnormalities, and frontal release signs. He also had conjunctivitis (Fig. 1). When the meningeal signs gradually resolved and the patient was extubated, he was noted to have decreased short-term memory, hypomania, hyperphagia and insomnia, mild cerebellar signs, and mild weakness of the lower limbs. Over the next few days and weeks most of the symptoms gradually resolved. Three weeks after the onset of symptoms he had uveitis, which resolved with topical corticosteroids. Magnetic resonance imaging of the brain showed multiple punctate microvascular lesions in the white matter (Fig. 2). When seen 7 months later, he had chronic fatigue and decreased executive function [25]. Assessment of severity of neurological symptoms necessitates the use of a numerical scale; however, 


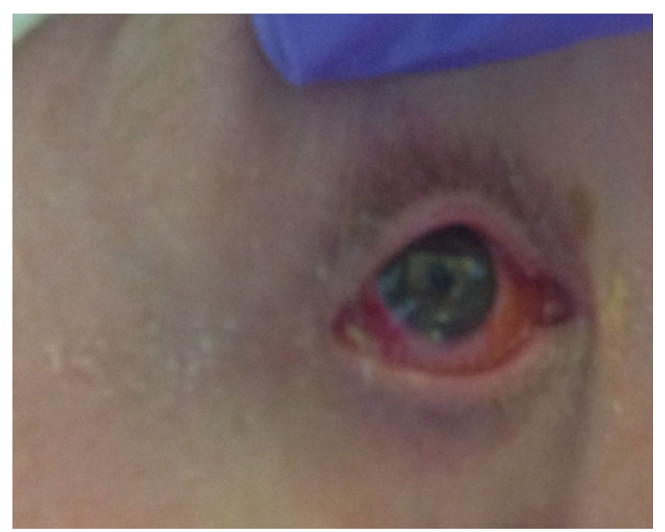

Fig. 1 Conjunctivitis in a patient with acute Ebola virus infection

existing scales do not take into account symptoms such as meningitis, hypomania, and hyperphagia. Hence, we have developed an Ebola scale that used the NIH's stroke scale and added another 16 points for the additional signs (Table 2).

Neurologic assessment of patients in an acute setting poses multiple challenges. The patient needs to be admitted to an isolation unit with intensive care facilities. The physician needs to be trained in biosafety procedures and how to dress and wear multiple layers of protective clothing (Fig. 3). The process of changing clothes can take nearly $30 \mathrm{~min}$. Only limited neurologic assessment is possible. For example, sensory examination and fundoscopy cannot be performed owing to the face shield. Ultimately, we were able to conduct an indirect ophthalmoscopy using an innovative technique [26]. Physicians who examined the patients were required to monitor and report their own temperature for 21 days and travel restrictions were imposed upon them.

\section{Laboratory Findings}

Confirmation of Ebola diagnosis is done by detection of Ebola RNA via reverse transcriptase polymerase chain reaction (RT-PCR) or through detection of viral antigens by enzyme-linked immunosorbent assay. RT-PCR is usually able to detect Ebola RNA within 3 days of symptom onset, but this may need to be repeated in PCR-negative patients who are suspected to have the disease, particularly early after symptom onset $[1,27]$. In the patient seen at the NIH, the viral load in the blood paralleled the severity of the neurological symptoms (Fig. 4) [25].

Laboratory abnormalities seem to be somewhat variable but may include leukopenia or leukocytosis (with leukopenia typically early in the disease and leukocytosis later on), and thrombocytopenia. Transaminase testing often reveals abnormalities, usually with a greater elevation in aspartate transaminase than alanine transaminase [18]. With the marked volume loss common in the recent outbreak, electrolyte derangements such as hypo- and hypernatremia, hypocalcemia, hypokalemia, and hypomagnesemia have often been reported [7]. Renal insufficiency and lactic acidosis may also be commonly seen. Coagulation abnormalities such as prolongation of international normalized ratio and partial thromboplastin time may also occur, although these laboratory abnormalities were not as prominent in this outbreak compared with others [18]. In cases of multiorgan failure, all of the above may be seen, often at markedly deranged values [20]. There are very few reports of cerebrospinal fluid (CSF) analysis during acute EVD. However, in 2 different cases of encephalitis related to EVD, CSF analysis revealed Ebola virus present in the CSF. In the first case, a lumbar puncture was performed early in the course of disease, revealing a viral load of $1 \times 10^{6}$ viral copies/ml and a normal cell count and glucose in the CSF [23]. In the second case, a lumbar puncture was performed at day 41 after EVD onset; Ebola virus was detected at a cycle threshold (CT) value of 37.6, but further CSF analysis was not available [24]. Although not typical laboratory analyses, cytokine analyses on patients with Ebola have in the past revealed a "cytokine storm", with increased proinflammatory cytokine and chemokine production in patients with Ebola, particularly in those with more severe disease [28].


Fig. 2 Magnetic resonance imaging scan of patient with Ebola meningoencephalitis: fluid-attenuated inversion recovery images were taken 3 weeks after onset of symptoms and after resolution of clinical signs of meningitis. Punctate high signal intensity lesions represent microvascular disease. There is also some associated cortical atrophy 
Table 2 Ebola neurological scale: 16 additional points to the National Institutes of Health stroke scale

\begin{tabular}{llll}
\hline Delirium & 0 & 1 & \\
\hline Seizures & 0 & 1 (focal) & 2 (generalized) 3 (status) \\
Mania & 0 & 1 (present) & \\
Meningitis & 0 & 1 (partial flexion) & 2 (no neck flexion) \\
Frontal release signs & 0 & 1 (present) & \\
Involuntary movements & 0 & 1 (myoclonus or asterixis) & 2 (myoclonus and asterixis) \\
Hyper-reflexia & 0 & 2 (spread) & 3 (sustained clonus) \\
Myopathy & 0 & 1 (myalgia) & 2 (generalized weakness), \\
& & & 3 (respiratory weakness) \\
\hline
\end{tabular}

\section{Pathology}

Owing to biosafety concerns, autopsies have not been performed on patients who have died of acute Ebola infection. However, microglial nodules and perivascular infiltrates involving both gray and white matter were noted in 2 cases of Marburg disease manifested as subacute encephalitis [29, 30]. Nonhuman primate studies of EVD show glial nodules or meningoencephalitis were observed in 5 of 6 animals surviving 3 weeks following infection. Glial nodules stained positive for viral antigen, suggesting microglial cells as a possible reservoir for virus in the brain [31].

\section{Mortality}

Ebola is one of the most highly fatal infectious diseases known to humans. In prior outbreaks, fatality has ranged from $25 \%$ with the Bundibugyo outbreak in Uganda in 2007 up to $89 \%$ with the Zaire strain outbreak in the Republic of Congo in 2001 [2]. Generally, mortality rates are higher in outbreaks due to the Zaire strain (70-90\% historically), with about $40 \%$ mortality seen in Bundibugyo, and about 50\% mortality in Sudan species of Ebola [27]. This current outbreak is caused by the Makona variant of the Zaire species of Ebola; however, a lower case fatality rate has been noted during this outbreak [32]. As of 17 February 2016, there have been 28,639 cases with 11,316 deaths during the recent outbreak, with a case fatality rate of about $40 \%$ [4]. This decreased mortality rate is of unclear significance as yet but is potentially due to a trend towards overall earlier access to treatment and more comprehensive supportive treatment, or in differences in the virulence of the current strain.

\section{Clinical Sequelae}

The long-term outcomes of Ebola survivors has been of significant recent interest. There have only been brief reports of these outcomes from prior Ebola outbreaks, including a study of 70 survivors from a 2007 outbreak in Uganda. These survivors, evaluated at approximately 29 months after infection, most commonly reported memory loss, retro-orbital pain, hearing loss, and arthralgias [33]. A longitudinal study followed a smaller group of survivors from the 1995 outbreak in what was then Zaire found primarily arthralgia and myalgia to be persistent problems in more than half of the cohort of 29 survivors when compared with uninfected household contacts [34]. Tellingly, the survivors reported a functional decline when compared with before the EVD outbreak. In comparison with the household contacts, the survivors were more likely to report a decline in both overall health $(70 \%$ vs $18 \%)$ and ability to work (70\% vs 7\%) [34].

From the current outbreak, there has been a growing interest in identifying the clinical outcomes of Ebola survivors. An ongoing cohort study from Sierra Leone of 277 survivors seen at a median of 121 days after ETU discharge specifically examined ocular, auditory, and musculoskeletal outcomes. Arthralgias were the most commonly reported symptom, present in $76 \%$ of the cohort. New ocular symptoms were reported in $60 \%$, and $18 \%$ had uveitis on slit-lamp and dilated fundus examinations. Furthermore, 24\% reported tinnitus, aural fullness, or hearing loss [35].

Neurologic sequelae are, unfortunately, less well characterized than systemic and ophthalmic outcomes. One recent study of Guinean survivors from the recent outbreak used a questionnaire administered either in person or over the telephone to collect data on a variety of persistent or new symptoms, and many of the questions focused on neurologic and psychiatric impairments since discharge from the ETU [36]. While the study was limited by the questionnaire design and the lack of neurologic examinations, neurologic symptoms were reported in a substantial number of participants during the subacute convalescent period (defined as 91-210 days) and included difficulty with concentration $(37.5 \%)$ or memory (21.3\%), headache $(29.2 \%)$, or dizziness $(6.3 \%)$.

A larger, longitudinal study is currently ongoing specifically to evaluate the neurologic outcomes in survivors of EVD from the recent outbreak in Liberia [37]. Approximately 150 survivors and 100 close contacts are being followed by a team of neurologists with serial 6-month follow-up visits. Of the 87 survivors initially examined by the team, weakness, headache, 


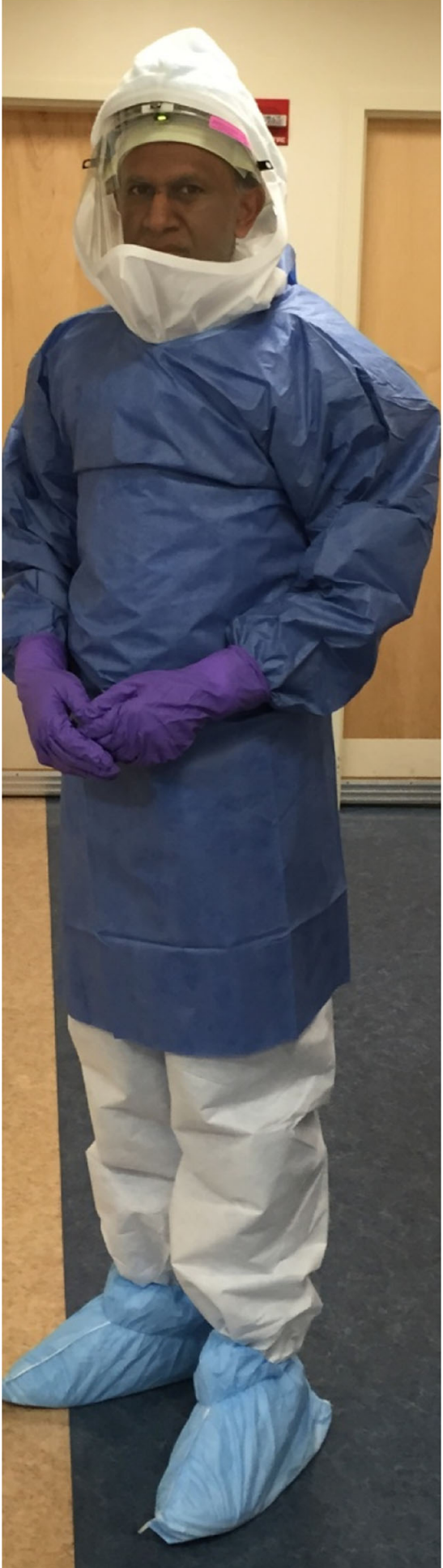

Fig. 3 Neurological assessment in an acute setting. Specialized training is needed in biosafety procedures and 3 layers of gloves impairs the ability to use fine touch and palpate. The face shield makes its difficult to do a fundoscopic evaluation. Sensory examination cannot be performed

memory loss, depressed mood, and myalgia were the most common symptoms. On neurologic examination, most participants had some degree of objective abnormality. The most common findings were impairments of either pursuits or saccades (nearly two-thirds of the cohort); tremor, abnormal reflexes or abnormal sensory findings in a third; and frontal release signs in a sixth. The cohort is enrolling survivors and contacts without selecting for neurologic symptoms; however, there have been other survivors seen by the team of neurologists with more overt neurologic manifestations. Focal deficits consistent with stroke have been seen in several survivors, including those with homonymous hemianopias, hemiparesis, and cranial nerve palsies. Similarly, some participants have a parkinsonian syndrome with rigidity, shuffling gait, and retropulsion on examination. It is evident from these detailed neurologic evaluations that a subset of survivors have more severe neurologic manifestations that persist after acute EVD infection.

It is important to note that most studies of Ebola survivors to date have been cross-sectional so it is unknown how persistent these findings will remain years after the acute infection. Longitudinal cohort studies, including the cohort study specifically addressing neurologic complications, are ongoing.

\section{Viral Persistence}

As this current outbreak of Ebola virus is the largest in history, there are many more survivors in whom to evaluate the various sequelae of EVD. Some of the most startling findings have been regarding the viral persistence of Ebola, which may sometimes be harbored in immune-privileged areas of the body such as the testes, placenta, eye, or central nervous system. In prior outbreaks, viral persistence in certain body fluids had been reported during the convalescent period. Ebola virus was isolated in breast milk and semen 15 days and 82 days, respectively, after disease onset during the convalescent phase, and Ebola RNA was detected in urine, feces, tears, and from vaginal fluid 23, 29, 22, and 33 days after disease onset $[6,38]$. It was also known that ocular manifestations could develop during convalescence, although these findings were only found in a small number of patients and relatively little was known about the nature of these ocular issues [39]. However, during the 2014 outbreak several systematic studies (some ongoing) and a number of cases of Ebola relapse in various parts of the body have alerted the community to the significance of viral persistence of this pathogen.

Since these initial studies of Ebola virus persistence in bodily fluids, several studies conducted during the recent outbreak support the findings of persistent Ebola in bodily fluids. Ebola viral RNA has recently been detected in convalescent patients' urine and sweat $[40,41]$. However, one of the most striking findings is the persistence of Ebola RNA in the semen for prolonged periods of time. A study of 93 male survivors found viral RNA in survivors up to 284 days after onset of 
Fig. 4 (A) A gradual and progressive decline in viral load was noted in the blood and urine. (B) The neurological symptoms were present at the time of onset of infection but deteriorated rapidly; however, most symptoms resolved with supportive care $\mathrm{CT}$ $=$ cycle threshold; $\mathrm{PCR}=$ polymerase chain reaction; $\mathrm{NIH}$, National Institutes of Health; MMSE $=$ Mini-Mental Status Evaluation

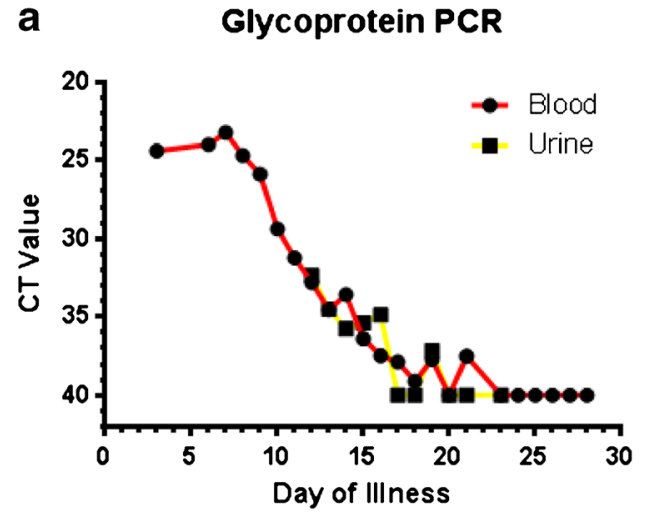

symptoms, although at decreasing rates over time (with all survivors who were tested at 2-3 months after onset having EBOV RNA-positive semen, $65 \%$ of survivors positive at $4-6$ months after onset, and $26 \%$ positive at 7-9 months after onset) [42]. These findings are of further interest given the potential for sexual transmission of EVD, as in the previously mentioned March 2015 case in Liberia [15]. Owing to risk of sexual transmission during convalescence, Ebola survivors are now recommended to practice safe sex with barrier protection for at least 12 months after recovery from EVD [43].

Although little is known about viral persistence in pregnant or lactating women, a recent case revealed some interesting findings. A pregnant woman treated at a Medecins Sans Frontières ETU in Guinea was described by Baggi et al. [44]. This 7-months-pregnant woman was treated for EVD and was EBOV negative by RT-PCR in the blood on day 8 after symptom onset and remained negative on day 10. Fetal movement and heartbeat were lost on day 11, labor was induced on day 15, and a stillborn baby was delivered. Despite the mother's negative EBOV results, high levels of EBOV RNA were found in the fetal blood, placenta, amniotic fluid, and meconium of the infant [44]. This case illustrates the potential need for special precautions and infection control during delivery of EVD survivors, particularly when temporally proximal to acute EVD.

The previous cases and studies illustrate the asymptomatic persistence of Ebola virus, with the potential of transmission of the disease to uninfected people. Another concern about viral persistence that has arisen since the recent outbreak is relapse or recurrence of EVD in a recovered survivor. A recent report details a 43-year-old American physician who had clinically recovered from EVD 9 weeks prior to developing severe unilateral uveitis. Aqueous humor was obtained from the affected eye, in which viable Ebola virus was detected [45]. While ocular manifestations including uveitis are known to occur in EVD survivors during the convalescent phase, these findings have been thought to be related to delayed immunological

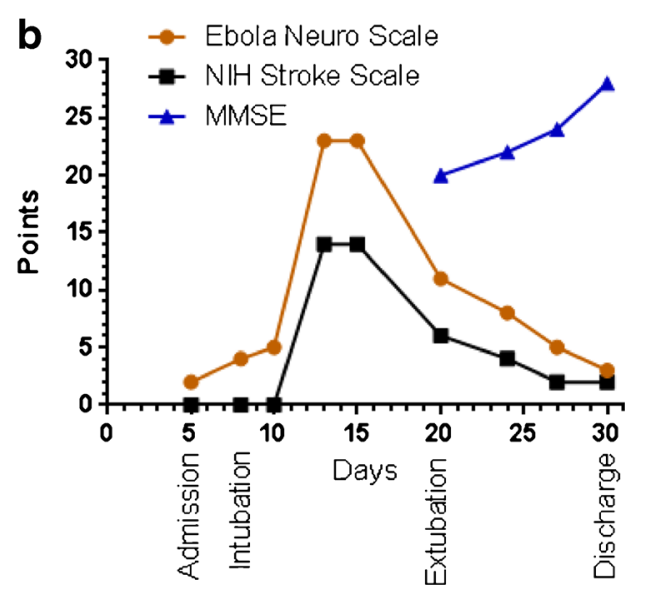

factors. This case suggests that viral recurrence may be a potential cause of uveitis, warranting further study.

More recently, a Scottish nurse was reported to have developed neurological symptoms consistent with meningoencephalitis 9 months after recovery from EVD. She was found to be PCR-positive for Ebola virus in both CSF and serum, and she was treated with an experimental therapy [46]. While there are very few reports to date consistent with Ebola recrudescence, it is possible that these cases are under-reported, as the majority of survivors live in West Africa with less access to healthcare. Nevertheless, an additional concern from these EVD relapse cases is the potential for EVD transmission during viral recurrence (although, at least regarding the 2 cases above, casual contact with either aqueous or CSF does not typically occur). While further study of Ebola virus persistence is needed in humans, and is ongoing in some natural history studies, we can supplement some of this knowledge with findings in nonhuman primate studies. Alves et al. [47] reported a rhesus macaque infected with Ebola virus which then recovered from infection without treatment; however, the animal subsequently developed conjunctivitis and clinical worsening, prompting sacrifice. At necropsy, lesions were found in the eye which stained strongly for Ebola virus antigen on immunohistochemistry; moreover, the brain, stomach, and pancreas also showed evidence of Ebola virus antigen [47]. Although studies with Ebola in nonhuman primates are typically ended before late complications occur in the animals, these animal models could provide some meaningful insight into viral persistence of Ebola.

\section{Therapeutics}

Treatment of EVD requires not only a skilled and knowledgeable team able to monitor and care for the acutely ill patient with EVD, but also to protect the healthcare staff from infection. Personal protective equipment (PPE) is required of every 
person with the potential to come into contact with infectious fluids. In the acute phase, when the potential for transmission is exceedingly high, full barrier PPE is needed. Proper donning and doffing of the PPE is vital, and various public health organizations have published detailed guidelines that should be followed during the care of every patient with known or suspected acute EVD.

\section{Treatment of Acute EVD}

Despite vast differences in available resources in the different countries where acute EVD has been treated, the fundamental principles of care are the same: isolation, monitoring, and supportive care. Isolating patients suspected of and confirmed as having EVD is critical to prevent transmission. In resourcelimited settings, the ETUs largely consisted of facilities often far removed from the city center. Patients were assessed and triaged based on volume status, evidence of organ failure, and ability for self-care [11]. Those with hypovolemia, not in organ failure, and able to care for themselves were the focus of management because they were most likely to improve in the setting where intravenous fluid management was limited. Antiemetics, antidiarrheals, and oral rehydration solutions are all staples of countering the gastrointestinal losses associated with acute EVD $[11,20]$.

\section{Antiviral Therapeutics}

Beyond monitoring and supportive care, Ebola-specific therapeutics have been evaluated during this recent outbreak. Plasma or whole blood from survivors of severe infections have been successfully used for other emerging outbreaks, most notably for influenza [48]. The utility of this convalescent plasma or whole blood is not fully known currently. A study from Guinea of 99 patients with confirmed EVD who each received, within 2 days of diagnosis, 2 consecutive doses of convalescent plasma from 2 different EVD survivors found a nonsignificant decrease in the risk of death with a risk difference of $-3 \%$ when compared with historic controls from the same outbreak and when adjusted for age and the PCR CT value [49].

ZMapp (Mapp Biopharmaceutical, San Diego, CA, USA), a triple monoclonal antibody cocktail that has shown promise based on nonhuman primate data, was studied during the recent outbreak. A randomized, placebo-controlled trial enrolled 72 patients with EVD and the drug was given at a mean of 4.2 days after symptom onset. Thirty-seven percent of patients who were randomized to receive standard of care died versus $22 \%$ of those who receives standard of care + Zmapp. The results were not statistically significant; however, the study did not meet its enrollment target of 200 patients by the time the outbreak ended [50].
The antiviral drug favipiravir was studied in Guinea in 80 patients with EVD; however, there was no placebo control group to assess efficacy. The mortality rate of $54 \%$ in those who received favipiravir was not statistically different than the mortality rate of $58 \%$ among "historic" controls from the same outbreak and area that the authors used for analysis [51]. The authors suggest that those who received favipiravir and had a higher pretreatment $\mathrm{CT}$ value had a lower mortality than historic controls; however, they also note that the study was not adequately powered or designed to detect such an effect.

\section{Vaccines}

A number of vaccines against Ebola have undergone preclinical studies and subsequent clinical trials in humans. The vaccine CAd3-EBOV, which uses an attenuated version of a chimpanzee adenovirus, underwent phase I trials in the USA and UK, and a phase II trial in Mali and showed strong immunogenicity and there were no significant adverse effects in the early trials [52]. Similarly, a vesicular stomatitis virus that has been modified to express an EBOV glycoprotein, rVSV-EBOV, underwent phase I studies in multiple countries followed by a phase II trial in Guinea. Subsequently, phase III trials have been underway in Guinea (rVSV-EBOV), Sierra Leone (rVSV-EBOV), and Liberia (rVSV-EBOV and cAD3-EBOV as separate arms) [53, 54]. All results have been promising; however, measuring efficacy of these vaccines has been limited by the declining number of new Ebola cases in West Africa.

\section{Conclusion: Goals and Challenges}

There are a number of unique challenges associated with Ebola. Given its high consequences and biosafety level 4 status, it is a difficult pathogen to study. Although some potential therapies are in development, treatment is largely supportive at this point, and mortality remains very high. The most important interventions in an outbreak remain public health initiatives such as containment, hygiene, and prevention of transmission. However, this recent outbreak was considerably challenging to contain, as it occurred in highly and densely populated areas with poor health infrastructure. Moreover, many of the populations in the affected areas were characterized by cultures rich in tribal ritual, as well as a strong sense of community; these aspects initially led to local distrust and skepticism of outside-led public health initiatives, hindering the relief response and attempts of containment. However, with improved community-based initiatives taking cultural traditions and beliefs into account and incorporating community leaders, this outbreak was eventually controlled, albeit after 2 years, tens of thousands of cases, and $>11,000$ deaths from the virus [55]. 
The magnitude of this outbreak has brought to light many aspects of this virus which were previously either unknown or vague, such as acute, as well as persistent, neurologic issues and virologic persistence in various areas of the body, including the central nervous system. These issues require considerable further research; however, with further longitudinal study and close follow-up of Ebola survivors, in combination with in vitro and animal model studies of Ebola, more answers will hopefully be found in regard to this fascinating and deadly pathogen in the near future.

Required Author Forms Disclosure forms provided by the authors are available with online version of this article.

\section{References}

1. Goeijenbier M, van Kampen JJ, Reusken CB, Koopmans MP, van Gorp EC. Ebola virus disease: a review on epidemiology, symptoms, treatment and pathogenesis. Neth J Med 2014;72:442-448.

2. Shears P, O'Dempsey TJ. Ebola virus disease in Africa: epidemiology and nosocomial transmission. J Hosp Infect 2015;90:1-9.

3. Luby JP, Sanders CV. Green monkey disease ("Marburg virus" disease): a new zoonosis. Ann Intern Med 1969;71:657-660.

4. World Health Organization. Ebola Situation Report 17 February 2016. Available from: http://apps.who.int/ebola/currentsituation/ebola-situation-report-17-february-2016. Accessed February 19, 2016.

5. Martines RB, Ng DL, Greer PW, Rollin PE, Zaki SR. Tissue and cellular tropism, pathology and pathogenesis of Ebola and Marburg viruses. J Pathol 2015;235:153-174.

6. Bausch DG, Towner JS, Dowell SF, et al. Assessment of the risk of Ebola virus transmission from bodily fluids and fomites. J Infect Dis 2007;196(Suppl. 2):S142-S147.

7. Fischer WA, Uyeki TM, Tauxe RV. Ebola virus disease: What clinicians in the United States need to know. Am J Infect Control 2015;43:788-793.

8. Rewar S, Mirdha D. Transmission of ebola virus disease: an overview. Ann Glob Health 2014;80:444-451.

9. Klompas M, Yokoe DS. The Ebola transmission paradox. Am J Infect Control 2015;43:786-787.

10. Towner JS, Rollin PE, Bausch DG, et al. Rapid diagnosis of Ebola hemorrhagic fever by reverse transcription-PCR in an outbreak setting and assessment of patient viral load as a predictor of outcome. $\mathrm{J}$ Virol 2004; 78:4330-4341.

11. Chertow DS, Kleine C, Edwards JK, Scaini R, Giuliani R, Sprecher A. Ebola virus disease in West Africa - clinical manifestations and management. N Engl J Med 2014;371:2054-2057.

12. Piercy TJ, Smither SJ, Steward JA, Eastaugh L, Lever MS. The survival of filoviruses in liquids, on solid substrates and in a dynamic aerosol. J Appl Microbiol 2010;109:1531-1539.

13. Brainard J, Hooper L, Pond K, Edmunds K, Hunter PR. Risk factors for transmission of Ebola or Marburg virus disease: a systematic review and meta-analysis. Int J Epidemiol 2015;45:102-116.

14. Eggo RM, Watson $\mathrm{CH}$, Camacho A, Kucharski AJ, Funk S, Edmunds WJ. Duration of Ebola virus RNA persistence in semen of survivors: population-level estimates and projections. Euro Surveill 2015;20(48)

15. Mate SE, Kugelman JR, Nyenswah TG, et al. molecular evidence of sexual transmission of Ebola virus. N Engl J Med 2015;373: 2448-2454.
16. Singh G, Kumar A, Singh K, Kaur J. Ebola virus: an introduction and its pathology. Rev Med Virol 2015 Nov 12 [Epub ahead of print].

17. Schou S, Hansen AK. Marburg and Ebola virus infections in laboratory non-human primates: a literature review. Comp Med 2000;50:108-123.

18. West TE, von Saint André-von Arnim A. Clinical presentation and management of severe Ebola virus disease. Ann Am Thorac Soc 2014;11:1341-1350.

19. Gatherer D. The 2014 Ebola virus disease outbreak in West Africa. J Gen Virol 2014;95:1619-1624.

20. Fowler RA, Fletcher T, Fischer WA, et al. Caring for critically ill patients with ebola virus disease. Perspectives from West Africa. Am J Respir Crit Care Med 2014;190:733-737.

21. Khan AS, Tshioko FK, Heymann DL, et al. The reemergence of Ebola hemorrhagic fever, Democratic Republic of the Congo, 1995. Commission de Lutte contre les Epidémies à Kikwit. J Infect Dis 1999;179(Suppl. 1):S76-S86.

22. Bwaka MA, Bonnet MJ, Calain P, et al. Ebola hemorrhagic fever in Kikwit, Democratic Republic of the Congo: clinical observations in 103 patients. J Infect Dis 1999;179(Suppl. 1):S1-S7.

23. Sagui E, Janvier F, Baize S, et al. severe ebola virus infection with encephalopathy: evidence for direct virus involvement. Clin Infect Dis 2015;61:1627-1628.

24. Howlett P, Brown C, Helderman T, et al. Ebola virus disease complicated by late-onset encephalitis and polyarthritis, Sierra Leone. Emerg Infect Dis 2016;22:150-152.

25. Chertow DS, Nath A, Suffredini AF, et al. Severe meningoencephalitis in a case of Ebola virus disease. Ann Intern Med 2016 Apr 5 [Epub ahead of print].

26. Haddock LJ, Kim DY, Mukai S. Simple, inexpensive technique for high-quality smartphone fundus photography in human and animal eyes. J Ophthalmol 2013;2013:518479.

27. Kaushik A, Tiwari S, Dev Jayant R, Marty A, Nair M. Towards detection and diagnosis of Ebola virus disease at point-of-care. Biosens Bioelectron 2016;75:254-72.

28. Wauquier N, Becquart P, Padilla C, Baize S, Leroy EM. Human fatal Zaire Ebola virus infection is associated with an aberrant innate immunity and with massive lymphocyte apoptosis. PLoS Negl Trop Dis 2010;4.

29. Bechtelsheimer H, Korb G, Gedigk P. [The "Marburg-virus"-hepatitis. Studies in man and guinea pigs]. Virchows Arch A Pathol Pathol Anat 1970;351:273-290.

30. Slenczka WG. The Marburg virus outbreak of 1967 and subsequent episodes. Curr Top Microbiol Immunol 1999;235:49-75.

31. Larsen T, Stevens EL, Davis KJ, et al. Pathologic findings associated with delayed death in nonhuman primates experimentally infected with Zaire Ebola virus. J Infect Dis 2007;196(Suppl. 2): S323-S328.

32. de La Vega MA, Stein D, Kobinger GP. Ebolavirus evolution: past and present. PLoS Pathog 2015;11:e1005221.

33. Clark DV, Kibuuka H, Millard M, et al. Long-term sequelae after Ebola virus disease in Bundibugyo, Uganda: a retrospective cohort study. Lancet Infect Dis 2015;15:905-912

34. Rowe AK, Bertolli J, Khan AS, et al. Clinical, virologic, and immunologic follow-up of convalescent Ebola hemorrhagic fever patients and their household contacts, Kikwit, Democratic Republic of the Congo. Commission de Lutte contre les Epidémies à Kikwit. J Infect Dis 1999 179(Suppl 1):S28-S35.

35. Mattia JG, Vandy MJ, Chang JC, et al. Early clinical sequelae of Ebola virus disease in Sierra Leone: a cross-sectional study. Lancet Infect Dis 2016;16:331-338.

36. Qureshi AI, Chughtai M, Loua TO, et al. Study of Ebola virus disease survivors in Guinea. Clin Infect Dis 2015;61:1035-1042.

37. Bowen L, Smith B, Steinbach S, Billioux BJ, et al. Survivors of Ebola virus disease have persistent neurologic deficits. 2016. Available from: 
https://www.aan.com/PressRoom/Home/GetDigitalAsset/12003 [abstract].

38. Rodriguez LL, De Roo A, Guimard Y, et al. Persistence and genetic stability of Ebola virus during the outbreak in Kikwit, Democratic Republic of the Congo, 1995. J Infect Dis 1999;179(Suppl. 1): S170-S176.

39. Kibadi K, Mupapa K, Kuvula K, et al. Late ophthalmologic manifestations in survivors of the 1995 Ebola virus epidemic in Kikwit, Democratic Republic of the Congo. J Infect Dis 1999;179(Suppl. 1):S13-S14.

40. Kreuels B, Wichmann D, Emmerich P, et al. A case of severe Ebola virus infection complicated by gram-negative septicemia. $\mathrm{N}$ Engl $\mathrm{J}$ Med 2014;371:2394-2401.

41. Lyon GM, Mehta AK, Varkey JB, et al. Clinical care of two patients with Ebola virus disease in the United States. N Engl J Med 2014;371:2402-2409.

42. Deen GF, Knust B, Broutet N, et al. Ebola RNA persistence in semen of Ebola virus disease survivors - preliminary report. $\mathrm{N}$ Engl J Med 2015 Oct 14 [Epub ahead of print].

43. World Health Organization. Interim advice on the sexual transmission of the Ebola virus disease 21 January 2016. Available from: http://www.who.int/reproductivehealth/topics/rtis/ebola-virussemen/en/. Accessed February 25, 2016.

44. Baggi FM, Taybi A, Kurth A, et al. Management of pregnant women infected with Ebola virus in a treatment centre in Guinea, June 2014. Euro Surveill 2014;19:pii: 20983.

45. Varkey JB, Shantha JG, Crozier I, et al. Persistence of Ebola virus in ocular fluid during convalescence. N Engl J Med 2015;372:24232427.

46. MacIntyre CR, Chughtai AA. Recurrence and reinfection - a new paradigm for the management of Ebola virus disease. Int J Infect Dis 2016;43:58-61.

47. Alves DA, Honko AN, Kortepeter MG, et al. Necrotizing scleritis, conjunctivitis, and other pathologic findings in the left eye and brain of an Ebola virus-infected rhesus macaque (Macaca mulatta) with apparent recovery and a delayed time of death. J Infect Dis 2016;213:57-60.

48. World Health Organization. Use of convalescent whole blood or plasma collected from patients recovered from Ebola virus disease for transfusion, as an empirical treatment during outbreaksSeptember 2014. Available from: http://www.searo.who. int/entity/emerging_diseases/ebola/who_his_sds_2014.8_eng.pdf. Accessed March 7, 2016.

49. van Griensven J, Edwards T, de Lamballerie X, et al. Evaluation of convalescent plasma for Ebola virus disease in Guinea. N Engl J Med 2016;374:33-42.

50. Davey R. PREVAIL II: a randomized controlled trial of ZMapp ${ }^{\mathrm{TM}}$ in acute Ebola virus infection [abstract]. In: Conference on Retroviruses and Opportunistic Infections; Feb 22-25, 2016; Boston, MA.

51. Sisoko D, Laouenan C, Folkesson E, et al. Experimental treatment with favipiravir for Ebola virus disease (the JIKI Trial): a historically controlled, single-arm proof-of-concept trial in Guinea. PLoS Med 2016;13(3).

52. Ledgerwood JE, DeZure AD, Stanley DA, et al. Chimpanzee adenovirus vector Ebola vaccine - preliminary report. N Engl J Med 2014 Nov 26 [Epub ahead of print].

53. Henao-Restrepo AM, Longini IM, Egger M, et al. Efficacy and effectiveness of an rVSV-vectored vaccine expressing Ebola surface glycoprotein: interim results from the Guinea ring vaccination cluster-randomised trial. Lancet 2015;386:857-866.

54. Bolay F. A randomized controlled trial of the safety and immunogenicity of two ebola vaccines. Presented in: Conference on Retroviruses and Opportunistic Infections; February 22-25, 2016; Boston, MA.

55. Fallah M, Dahn B, Nyenswah TG, et al. Interrupting Ebola transmission in Liberia through community-based initiatives. Ann Intern Med 2016;164:367-369. 